\title{
ZONEAMENTO URBANO E LOTEAMENTOS RECENTES NA CIDADE DE PIRACICABA
}

\section{URBAN ZONING AND EMERGING LOTS IN PIRACICABA}

\author{
José Diego Gobbo Alves ${ }^{1}$
}

Roberto Braga ${ }^{2}$

\section{RESUMO}

A atuação do mercado imobiliário nas cidades brasileiras tende a ditar o ritmo de urbanização do território e, consequentemente, tem papel ativo na determinação da ocupação e do uso do solo urbano. O Estado assume uma posição contraditória nesse processo, pois ao mesmo tempo que é o responsável pelo planejamento do território que deveria ser justo para toda a sociedade atua, paralelamente, viabilizando a reprodução do capital pelos agentes imobiliários. O objetivo deste trabalho é a avaliação da relação entre o zoneamento urbano, como instrumento urbanístico de uso e ocupação de solo e o surgimento de novos loteamentos na cidade de Piracicaba - São Paulo. Os resultados da análise apontaram que cerca de $40 \%$ dos loteamentos aprovados no período de 2006 a 2016 o foram em áreas de ocupação controlada devido às especificidades físicas de fragilidade ambiental. Em contrapartida, zonas de adensamento prioritário permanecem com vazios urbanos, áreas dotadas de infraestruturas e equipamentos sociais, isto é, preparadas para absorver os loteamentos aprovados no período.

Palavras-chave: Mercado imobiliário. Zoneamento urbano. Piracicaba - São Paulo.

\section{ABSTRACT}

The real estate market action in the Brazilian cities tends to rhythm the urbanization of the territory and, consequently, has a role in the determination of land use and

\footnotetext{
${ }^{1}$ Bacharel em Geografia/Universidade Estadual Paulista-Rio Claro, Brasil jdgobboalves@gmail.com

${ }_{2}^{2}$ IGCE-Universidade Estadual Paulista/Rio Claro, Brasil

rbraga@rc.unesp.br
}

Número Especial da Revista Estudos Geográficos - XIII Seminário da Pós-Graduação em Geografia, Rio Claro, 15(0): 17-33, jan./jun. 2017 (ISSN 1678—698X) http://www.periodicos.rc.biblioteca.unesp.br/index.php/estgeo 
occupation. The State assumes a contradictory position in this process, while it is responsible for the planning of the territory that should be fair for the whole of society, it also enables reproduction of capital by real estate agents. Thus, the purpose of the work is an evaluation of the relationship between urban zoning, as an urban instrument of land use and occupation, and the emergence of new lots in the city of Piracicaba - São Paulo. The results of this analysis indicated that approximately $40 \%$ of all lots approved in the period from 2006 to 2016 were approved in areas of controlled occupation due to the physical specificities of environmental fragility. On the other hand, priority densification areas remain with urban voids, areas with infrastructures and social facilities, prepared to absorb the allotments approved in the period.

Keywords: Real estate market. Urban zoning. City of Piracicaba - São Paulo

\section{INTRODUÇÃO}

As cidades médias brasileiras apresentam uma tendência de crescimento espacial da área urbana para a periferia, fenômeno que não é recente nas grandes cidades, observado nas cidades médias a partir da segunda metade do século XX. Este crescimento pode impactar significativamente o meio ambiente, principalmente quando esta expansão se dá de forma desordenada e para áreas de fragilidade ambiental.

Estas características de crescimento espacial demonstram a necessidade da avaliação dos instrumentos urbanísticos, bem como de estudos da sua aplicabilidade no território pelo Estado, principal agente da política urbana. O Plano Diretor, portanto, aparece como o principal instrumento urbanístico, em escala municipal, que reúne as diretrizes gerais de uso e ocupação do solo para o ordenamento e planejamento territoriais.

Santos (2003) afirma que o planejamento urbano é um importante instrumento para a manutenção e o agravamento dos problemas urbanos enfrentados hoje. Dentre esses, Monte-Mor (2007) cita como exemplo a atuação do Banco Nacional da Habitação (BNH) como agravante da supervalorização de terras urbanas e periferização da população nas cidades, o que mostra que o planejamento urbano adotado pelo Estado pode impactar negativamente o território.

Em relação à viabilização da reprodução e acúmulo de capital, o Estado dota o território de infraestruturas e equipamentos sociais que permitem maior dinamismo dos agentes hegemônicos ou, ainda, se omite da realização de políticas públicas para atenuar a ação desses agentes, facilitando suas ações (MAGALHÃES, FILHO e SILVA, 2011).

Número Especial da Revista Estudos Geográficos - XIII Seminário da Pós-Graduação em Geografia, Rio Claro, 15(0): 17-33, jan./jun. 2017 (ISSN 1678—698X) http://www.periodicos.rc.biblioteca.unesp.br/index.php/estgeo 
Nesse sentido, o propósito deste artigo é avaliar a relação do zoneamento urbano como instrumento de gestão e ordenamento do uso e ocupação do solo, com a produção de novos loteamentos na cidade de Piracicaba entre 2006 e 2016, analisando se a localização dos mesmos segue as especificidades ambientais das zonas descritas no Plano Diretor. O recorte temporal deu-se a partir da aprovação do Plano Diretor do município, ocorrida em 2006, portanto, trata-se de uma avaliação dos 10 anos de vigência do instrumento.

O município de Piracicaba está localizado no interior do estado de São Paulo, cerca de $170 \mathrm{~km}$ da capital paulista (Figura 1). Possui uma área de $1.378,50 \mathrm{~km}^{2}$, tendo uma área urbana de 228,04 $\mathrm{km}^{2}$ e uma área rural de 1.150,46 $\mathrm{km}^{2}$. Segundo a caracterização do Instituto Brasileiro de Geografia e Estatística (2016), Piracicaba é considerada uma cidade média que abrange uma população de aproximadamente 370 mil habitantes.

Figura 1 - Localização do município de Piracicaba - São Paulo.

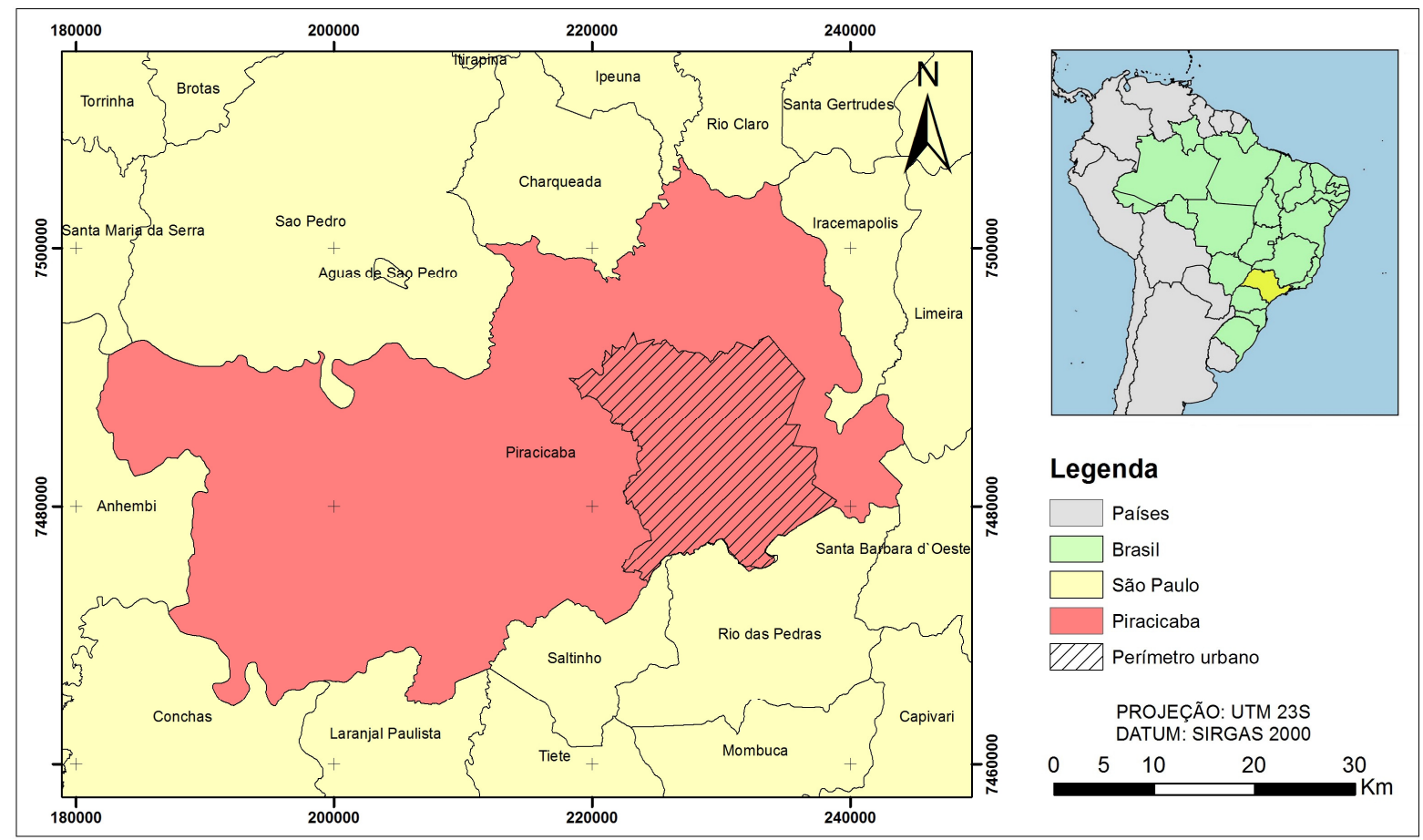

Fonte: IBGE, 2016. Elaboração: Os autores, 2016.

Pólo industrial e de desenvolvimento científico, o município comporta um parque industrial diversificado destacando-se os setores metalúrgicos, mecânico, agroindústrias, elétrico, laticínios, papel e celulose, têxteis e alimentícios. O setor de serviços é de grande importância para a economia da cidade, localizado na área central, bem como centros e corredores comerciais dos bairros (MONTEIRO,2009).

Observa-se na cidade a mesma tendência de crescimento das cidades médias brasileiras, tendo um significativo crescimento espacial da mancha urbana para a

Número Especial da Revista Estudos Geográficos - XIII Seminário da Pós-Graduação em Geografia, Rio Claro, 15(0): 17-33, jan./jun. 2017 (ISSN 1678-698X) http://www.periodicos.rc.biblioteca.unesp.br/index.php/estgeo 
periferia que, paralelamente, se dá descontínuo ao centro urbano consolidado. $O$ crescimento urbano do município intensificou-se a partir da década de 1940, principalmente pelas mudanças na agricultura do interior paulista, com a mecanização do campo e as migrações campo-cidade e inter-regionais. Dessa forma, nas décadas seguintes, enquanto o crescimento da população geral do município era de $0,65 \%$ ao ano, a população da área urbana crescia $3,34 \%$ e a população rural diminuía 2,13\% (MONTEIRO, 2009).

Devido a esse processo, a taxa de urbanização do município em 1980 já era alta, com $92,35 \%$, aumentando, em 2014 , para $98,04 \%$. Essa rápida urbanização do município, processo visto em diversas cidades brasileiras, acarretou em uma ocupação periférica desordenada que pode ser verificada atualmente. Aliado ao processo migratório tem-se que,

[...] a partir dos anos 60, a cidade de Piracicaba começa a se expandir de forma fragmentada e atingir áreas distantes da ocupação dos 200 anos anteriores de sua história, por intermédio da abertura de novos loteamentos públicos e privados. Este processo foi acompanhado pela extensão progressiva do perímetro urbano, viabilizando legalmente o espraiamento da malha da cidade e favorecendo a especulação imobiliária. (PÓLIS, 2003, p.20)

Sendo assim, a cidade sofre com um crescimento urbano desordenado desde a segunda metade do século $\mathrm{XX}$, período em que não apresentava corpo técnico qualificado para gestão e ordenamento territoriais, mesmo tendo dois Planos Diretores aprovados nas décadas de 1980 e 1990.

O artigo está estruturado em três partes: a primeira discorre sobre a metodologia para a elaboração do trabalho; a segunda integra uma revisão bibliográfica sobre o zoneamento urbano e o mercado imobiliário com o estudo de caso, e a última expressa as considerações finais dos autores.

\section{METODOLOGIA}

Para a realização do estudo, foi realizada uma revisão bibliográfica através do levantamento de artigos, livros, teses, dissertações e documentos de domínio público. Além disso, foram levantados dados secundários complementares às análises.

Os dados sobre os loteamentos aprovados no município foram coletados no site do Instituto de Pesquisa e Planejamento de Piracicaba (IPPLAP), em que se apresenta a quantidade de loteamentos aprovados em cada ano e sua localização na cidade.

Número Especial da Revista Estudos Geográficos - XIII Seminário da Pós-Graduação em Geografia, Rio Claro, 15(0): 17-33, jan./jun. 2017 (ISSN 1678—698X) http://www.periodicos.rc.biblioteca.unesp.br/index.php/estgeo 
Para o mapeamento temático do zoneamento da Macrozona Urbana, utilizou-se um arquivo em .dwg coletado no IPPLAP, tendo sido extraída em tif a base do zoneamento na cidade. Posteriormente, a imagem foi trabalhada no software de SIG QGIS 2.18 para a elaboração do mapa final com todos as zonas da macrozona urbana.

Em relação ao mapa temático de espacialização dos loteamentos em cada zona urbana, foi criado no software QGIS 2.18 uma feição em forma de ponto sobre o local em que cada novo loteamento pertence, para isso, utilizou-se os dados do IPPALP e verificações em campo sobre os novos loteamentos.

\section{O ZONEAMENTO URBANO COMO INSTRUMENTO DA POLÍTICA URBANA}

Os instrumentos da política urbana são leis que visam gerir e organizar o território, servindo de base para a realização das políticas públicas. São vários os instrumentos capazes de dar suporte para a tomada de decisão pelo poder público municipal e estes estão explícitos, no caso brasileiro, na Constituição Federal de 1988 e regulamentado no Estatuto da Cidade de 2001.

O principal instrumento de gestão urbana municipal é o Plano Diretor, que visa a organização explícita das diretrizes gerais de organização do território. Na história das cidades brasileiras, os municípios com plano diretor aprovado antes do Estatuto da Cidade não adotavam políticas efetivas de ordenamento territorial, o que ocasionou no crescimento urbano desordenado.

Anterior ao Estatuto da Cidade, já existia a obrigatoriedade da elaboração dos Planos Diretores, porém não havia nenhuma punição para os municípios que não elaborassem seus planos. No caso do estado de São Paulo, Braga (1995, p. 15) coloca que

A atual obrigatoriedade da elaboração de planos diretores
municipais, imposta pela Constituição Federal de 1988 (artigo 182),
não é novidade para os municípios paulistas. Já em 1967, a então
Lei Orgânica dos Municípios (Lei n. 9.842/67, posteriormente
alterada pelo Decreto Lei Complementar n. 09 de 31 de dezembro de
1969) determinava a obrigatoriedade da elaboração do plano diretor
(então denominado plano diretor de desenvolvimento integrado, o
chamado de PDDI) a todos os municípios paulistas, e mais ainda,
estabelecendo como punição aos municípios faltosos, a proibição de
auxílio financeiro pelo Estado.

Número Especial da Revista Estudos Geográficos - XIII Seminário da Pós-Graduação em Geografia, Rio Claro, 15(0): 17-33, jan./jun. 2017 (ISSN 1678—698X) http://www.periodicos.rc.biblioteca.unesp.br/index.php/estgeo 
Braga (1995) afirma, ainda, que os municípios paulistas que elaboraram os seus PDDI à época foram mais pelo caráter obrigatório do que como um documento norteador das diretrizes da política urbana. Essa característica gerou problemas que refletem na configuração espacial da cidade até os dias atuais.

Devido ao caráter tecnocrático que os Planos possuíam, os documentos criados não condiziam com a realidade e possibilidades locais, pois sua elaboração era delegada para empresas privadas terceiras (BRAGA, 1995). Por isso, é comum encontrarmos planos que não foram postos em prática, pois sem a participação popular e sem a presença de corpo técnico local capacitado, sua aplicabilidade os tornara inviáveis.

Partindo desse deficitário planejamento urbano das cidades brasileiras, destaca-se a participação popular na elaboração dos Planos, para os tornar mais próximos à realidade e aos problemas urbanos. No art. $40^{\circ}$ do Estatuto da Cidade que determina sobre o Plano Diretor, explicita-se que:

Art. 40. O plano diretor, aprovado por lei municipal, é o instrumento básico da política de desenvolvimento e expansão urbana. $\S 1^{\circ} \mathrm{O}$ plano diretor é parte integrante do processo de planejamento municipal, devendo o plano plurianual, as diretrizes orçamentárias e o orçamento anual incorporar as diretrizes e as prioridades nele contidas. $\S 2^{\circ} \mathrm{O}$ plano diretor deverá englobar 0 território do Município como um todo. $\S 3^{\circ}$ A lei que instituir o plano diretor deverá ser revista, pelo menos, a cada dez anos. $\S 4^{\circ}$ No processo de elaboração do plano diretor e na fiscalização de sua implementação, os Poderes Legislativo e Executivo municipais garantirão: I - a promoção de audiências públicas e debates com a participação da população e de associações representativas dos vários segmentos da comunidade; II - a publicidade quanto aos documentos e informações produzidos; III - o acesso de qualquer interessado aos documentos e informações produzidos. (BRASIL, 2001)

Rezende \& Ultramari (2006, p. 265) discorrem que o Estatuto da Cidade impõe aos planos diretores "[...] planejar democraticamente o futuro da cidade incorporando nessa discussão os diversos agentes sociais, econômicos e políticos que a compõem, buscando compromissos e definindo ações prioritárias."

O zoneamento é um dos instrumentos urbanísticos caracterizados nos Planos Diretores, primeiramente, observa-se um macrozoneamento do município em duas grandes Macrozonas: uma rural e outra urbana.

O zoneamento urbano, parte integrante do macrozoneamento urbano, delimita porções do território que terão políticas urbanas diferenciadas, partindo das suas características físicas, sociais e econômicas. Caracteriza-se como o instrumento responsável por determinar o uso do solo nas parcelas delimitadas, sendo "[...] os principais objetivos do zoneamento: o controle do crescimento urbano, a proteção de

Número Especial da Revista Estudos Geográficos - XIII Seminário da Pós-Graduação em Geografia, Rio Claro, 15(0): 17-33, jan./jun. 2017 (ISSN 1678-698X) http://www.periodicos.rc.biblioteca.unesp.br/index.php/estgeo 
áreas inadequadas à ocupação urbana e a minimização dos conflitos entre uso e atividades." (DAINEZI, 2012, p.57)

Braga (2001, p.99) coloca que "O zoneamento urbano é, certamente, o mais difundido instrumento urbanístico e, também, o mais criticado, tanto por sua eventual ineficácia, quanto por seus efeitos perversos (especulação imobiliária e segregação socioespacial)."

O Zoneamento é caracterizado como um procedimento urbanístico que regula o uso do solo em áreas de caráter homogêneo de interesse coletivo, portanto, regula como o solo será usado em áreas onde há interesses coletivos próximos.

Porém, ao se delimitar o zoneamento, deve-se considerar quais interesses coletivos homogêneos serão estabelecidos, uma vez que as políticas públicas podem levar a segregações e exclusões socioespaciais. Isso ocorre quando se pauta em interesses de apenas uma parcela da população; seus ideais podem não ser iguais aos da sociedade como um todo e podem ser excludentes.

Tem-se, então, o principal problema do zoneamento: quando realizado de modo tradicional e bem delimitado, pode aprofundar as desigualdades socioespaciais das cidades e intensificar processos de exclusão, segregação e autosegragação, ao determinar qual tipo de ocupação e uso pode ocorrer na área zoneada.

No município de Piracicaba, o Plano Diretor (Lei Complementar no186) e o zoneamento urbano foram aprovados em 2006, estando atualmente em processo final de revisão. Os princípios básicos em que o Plano se baseia são: a busca pela função social da cidade e da propriedade e a gestão democrática da cidade (Art. $3^{\circ}$ ).

Em relação ao mercado imobiliário, o PD objetiva coibir a especulação imobiliária, urbanizar adequadamente os vazios urbanos e integrar o território da cidade. Os instrumentos urbanos dispostos para coibir a especulação imobiliária e urbanizar os vazios urbanos são o Parcelamento, Edificação ou Utilização Compulsórios, IPTU progressivo no tempo e Desapropriação com pagamento em títulos da dívida pública (LEI COMPLEMENTAR, ㄲo186).

Quanto ao zoneamento urbano, estão dispostas no Título II Do ordenamento Territorial as regras para o macrozoneamento da cidade. Este, "fixa as regras fundamentais de ordenamento do território, definindo as áreas adensáveis e não adensáveis, de acordo com a capacidade de infraestrutura e a preservação do meio ambiente" (Art. 31).

A Macrozona urbana delimitada no Plano Diretor subdivide-se em 9 zonas, a saber: I - Zona de Adensamento Prioritário (ZAP); II - Zona de Adensamento Secundário (ZAS); III - Zona de Ocupação Controlada por Infra-Estrutura (ZOCIE); IV - Zona de Ocupação Controlada por Fragilidade Ambiental (ZOCFA); V - Zona de Ocupação Restrita (ZOR); VI - Zona Especial de Interesse da Paisagem Construída (ZEIPC);

Número Especial da Revista Estudos Geográficos - XIII Seminário da Pós-Graduação em Geografia, Rio Claro, 15(0): 17-33, jan./jun. 2017 (ISSN 1678—698X) http://www.periodicos.rc.biblioteca.unesp.br/index.php/estgeo 
VII - Zona Especial Industrial (ZEI); VIII - Zona Especial Institucional (ZEIT); IX Zona Especial Aeroportuária (ZEA). A figura 2 espacializa estas Zonas na Macrozona urbana do município.

Figura 2 - Zoneamento urbano da macrozona urbana de Piracicaba - São Paulo.

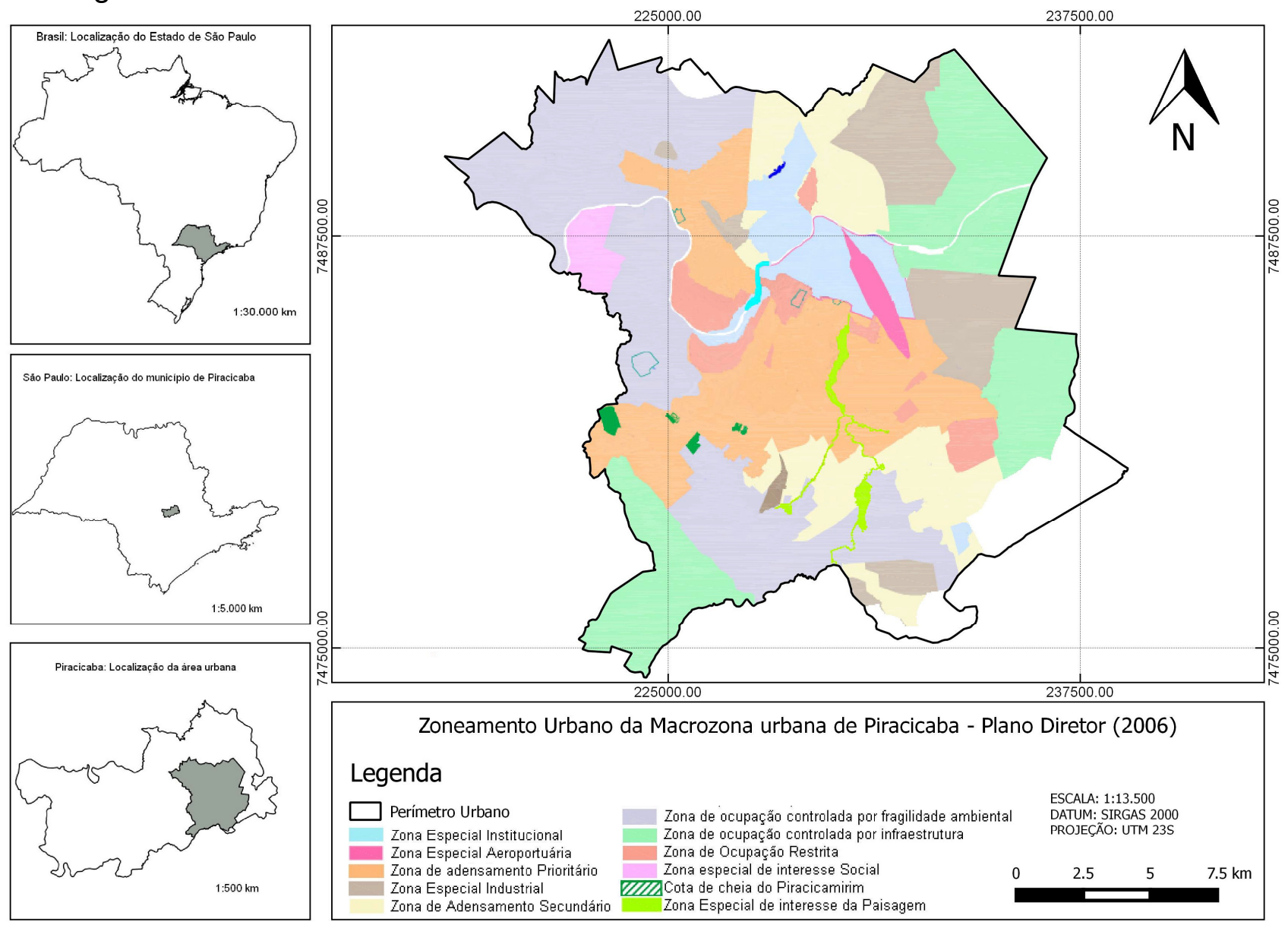

Fonte: Plano Diretor (2006). Elaboração: Os autores, 2016.

As Zonas demonstradas na Figura 2 apresentam características específicas de uso e ocupação de solo, compreendendo porções distintas do território.

A Zona de Adensamento Prioritário (ZAP) é caracterizada pela região mais consolidada da cidade, que não apresenta fragilidade ambiental e possui as melhores condições de infraestrutura (água e esgoto), acesso a transporte, educação, lazer e cultura. Já a Zona de Adensamento Secundário (ZAS) é composta por áreas da cidade que possuem infraestrutura, não apresentam fragilidade ambiental e concentram um grande número de vazios urbanos.

A Zona de Ocupação Controlada por Infraestrutura (ZOCIE) é composta por áreas do território sem fragilidade ambiental e condições insuficientes de infraestrutura (água e esgoto). A Zona de Ocupação Controlada por Fragilidade Ambiental

Número Especial da Revista Estudos Geográficos - XIII Seminário da Pós-Graduação em Geografia, Rio Claro, 15(0): 17-33, jan./jun. 2017 (ISSN 1678-698X) http://www.periodicos.rc.biblioteca.unesp.br/index.php/estgeo 
(ZOCFA), áreas do território que, embora possuam condições de infraestrutura, apresentam fragilidades ambientais, com solo sujeito a altos índices de erosão, não recomendável para o adensamento populacional.

A Zona de Ocupação Restrita (ZOR) compõe as áreas do território com infraestrutura deficitária e apresentam fragilidade ambiental, com alta declividade, altos índices de erosão do solo e forte presença de recursos hídricos.

Além das 5 Zonas citadas, há ainda 4 Zonas de caráter Especial, sendo: a) Zona Especial de Interesse da Paisagem Construída (ZEIPC), composta por áreas território que possuem ocupação consolidada, predominantemente, por uso residencial, de serviços e comércio de apoio à moradia, não sendo permitido o uso industrial, devendo ser observadas, ainda, de forma integral, as restrições particulares dos loteamentos, registradas na Serventia Imobiliária competente; b) Zona Especial Industrial (ZEI), áreas destinadas à instalação de indústrias incompatíveis com o uso residencial; c) Zona Especial Institucional (ZEIT), áreas que deverão ter os seguintes usos: educação, lazer, cultura, saúde, assistência social, administração, serviço público, comercial ou de prestação de serviços, vedado apenas o uso industrial e d) Zona Especial Aeroportuária (ZEA), a área do Aeroporto Municipal de Piracicaba delimitada pelas linhas limites do Plano de Zona de Proteção e do Plano de Zoneamento e Ruído.

Sendo assim, observa-se que o zoneamento da macrozona urbana visa realizar política urbana a partir das especificidades físicas, econômicas e sociais de cada porção do território, fundamental para uma maior integração deste e equilíbrio entre a sociedade, o meio ambiente e a economia.

\section{PRODUÇÃO DE NOVOS LOTEAMENTOS NAS CIDADES}

No Brasil, como salientado por Gonçalves (2010), o mercado de terras é uma criação estatal. $O$ regime de sesmarias, terminado meses antes da independência em 1822, não se adequava mais às condições encontradas no período, dessa forma, regulamentou-se aos sesmeiros a posse das terras que pertenciam ao Estado criando, então, a propriedade privada no Brasil.

Entre 1822 e 1850, ano da criação da Lei de Terras, houve uma apropriação desenfreada das terras públicas pelos agentes privados, estruturando parte dos latifúndios. Essa apropriação se deu devido à ausência do Estado na fiscalização das suas terras e da estrutura deficitária deste em relação aos cartórios locais que mantinham os registros de posse das mesmas (GONÇALVES,2010).

A Lei de Terras (1850) foi criada em um contexto de esgotamento da força de trabalho escravizada, devido às restrições impostas pela Inglaterra sobre o tráfico de

Número Especial da Revista Estudos Geográficos - XIII Seminário da Pós-Graduação em Geografia, Rio Claro, 15(0): 17-33, jan./jun. 2017 (ISSN 1678—698X) http://www.periodicos.rc.biblioteca.unesp.br/index.php/estgeo 
escravizados. Aliada a isso, a crise do café e a falta de habilidades técnicas da população escravizada demandava um aumento espacial da produção, necessitando um aumento da fronteira agrícola. Dessa forma,

Para resolver a questão da mão de obra, o governo proibiu o uso das terras de sua propriedade (chamadas de devolutas), a não ser através da compra do imóvel junto ao Estado - a Lei de Terras ganhava, assim, sustentação política. (GONÇALVES, 2010, p. 34)

Com a Lei de Terras, o governo buscava dar acesso à compra da terra apenas àqueles que possuíam condições para comprá-las criando, assim, uma massa de pessoas para trabalharem nessas terras, as quais não possuíam condições financeiras de acesso às mesmas. Com isso, foram criadas as bases para 0 mercado de terras no Brasil, tendo em vista que só poderiam ser obtidas pela a compra e venda registradas em cartórios.

Atualmente, o mercado imobiliário tem um papel central na produção e uso de solo urbano. Como colocado por Correa (1989), os agentes imobiliários hoje são um dos grupos dos atores hegemônicos que controlam parte da produção e ocupação do território. Ainda segundo Santos (2012), o capital imobiliário aparece como uma força hegemônica que coordena o espaço urbano através de lógicas próprias e submete o poder público local a atender e regulamentar suas intencionalidades. Dessa forma, o mercado imobiliário de terras acaba por ditar o ritmo de crescimento das cidades, processo comum nas grandes e médias cidades.

capital imobiliário não cria nenhum trabalho produtivo, como o capital industrial que investe na produção de bens, por exemplo, ele atua na compra e venda de terras (SANTOS, 2012). Singer (1979, p. 22) discutindo sobre a temática discorre que

O "capital" imobiliário é, portanto, um falso capital. Ele é, sem dúvida, um valor que se valoriza, mas a origem de sua valorização não é a atividade produtiva, mas a monopolização do acesso a uma condição indispensável àquela atividade.

Os agentes do mercado imobiliário podem ser caracterizados em três grupos: 1) os incorporadores; 2) as construtoras e 3) os proprietários de terras especulativas. Estes três grupos podem representar uma mesma pessoa física e jurídica ou pessoas física e jurídica diferentes, com os mesmos interesses ou com interesses opostos (CORREA, 1989).

Os incorporadores buscam terras rurais com um menor preço, geralmente na franja urbana, para vendê-las com um maior preço quando estas tornarem-se solo urbano através da expansão do perímetro urbano do município. Em muitos casos os

Número Especial da Revista Estudos Geográficos - XIII Seminário da Pós-Graduação em Geografia, Rio Claro, 15(0): 17-33, jan./jun. 2017 (ISSN 1678—698X) http://www.periodicos.rc.biblioteca.unesp.br/index.php/estgeo 
agentes incorporadores possuem relações com a gestão municipal para que possam comprar as terras rurais antes do perímetro urbano ser aumentado.

As construtoras visam comprar terras com menor preço para construir os empreendimentos imobiliários para os diversos estratos da sociedade. Já os proprietários de terras especulativas visam obter ganhos sem destinar uma função à terra, não estando preocupados com o ganho imediato sobre o capital investido. Portanto, os especuladores beneficiam-se das transformações territoriais de outros agentes, principalmente do Estado.

Ressalta-se que as ações do setor imobiliário estão estritamente vinculadas com as políticas macroeconômicas e, mesmo expressando-se de forma distinta territorialmente nas regiões brasileiras, podem ser vistas no país como um todo (MAGALHÃES; FILHO e SILVA, 2011).

O Estado tem um papel primordial na produção do espaço urbano, viabilizando a reprodução capitalista por meio de políticas públicas e pela sua estrutura de regulação (COSTA e MENDONÇA, 2011). Sua atuação varia de acordo com as necessidades impostas para o aumento da reprodução desse capital, sendo:

[...] importante que o investimento público nas áreas urbanas garanta as condições necessárias à acumulação, seja produzindo infraestruturas, seja renovando e atualizando os valores imobiliários e fundiários de áreas deterioradas, seja alterando mecanismos de regulação urbanística para criar patamares de lucratividade diferenciada (COSTA e MENDONÇA, 2011, p.9)

Sendo assim, o Estado tem papel fundamental na organização do território e, ao viabilizar as ações do mercado imobiliário, acaba por priorizar a reprodução do capital pelos agentes hegemônicos em detrimento do interesse coletivo da sociedade.

Avaliando a produção de novos loteamentos na cidade de Piracicaba, tem-se que entre os anos de 2006 e 2016 foram aprovados 84 novos loteamentos como apresenta a figura 3. 
Figura 3 - Loteamentos aprovados na cidade de Piracicaba entre 2006 e 2016.

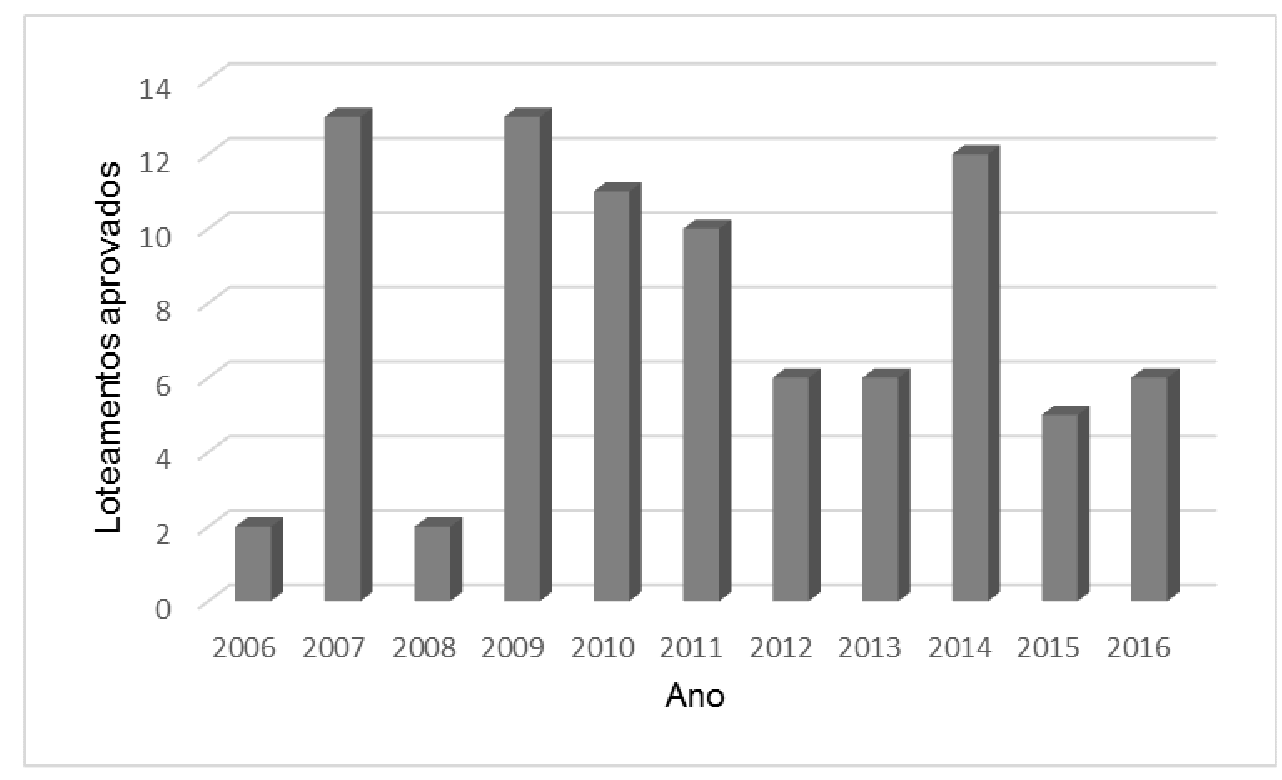

Fonte: IPPLAP, 2006.

Observa-se que há uma variação na quantidade de loteamentos aprovados, sendo os anos de 2006 e 2008 os que apresentam menores quantidades de loteamentos aprovados, 2 a cada ano. Os anos de 2007 e 2009 foram os que mais tiveram loteamentos aprovados, 13 por ano. Nos dois anos que antecedem o ano de 2006, foram aprovados 7 loteamentos em 2004 e 11 em 2005.

A possível justificativa para a queda de aprovação de loteamentos no ano de 2006 em que foram aprovados 2, é a aprovação do Plano Diretor do município que estava em processo final de elaboração. Os 84 loteamentos aprovados no período somam mais de 27 mil novos lotes.

A figura 4 apresenta os loteamentos aprovados de acordo com o zoneamento urbano estabelecido pelo Plano Diretor de 2006.

Número Especial da Revista Estudos Geográficos - XIII Seminário da Pós-Graduação em Geografia, Rio Claro, 15(0): 17-33, jan./jun. 2017 (ISSN 1678-698X) http://www.periodicos.rc.biblioteca.unesp.br/index.php/estgeo 
Figura 4 - Loteamentos aprovados nas zonas urbanas de Piracicaba.

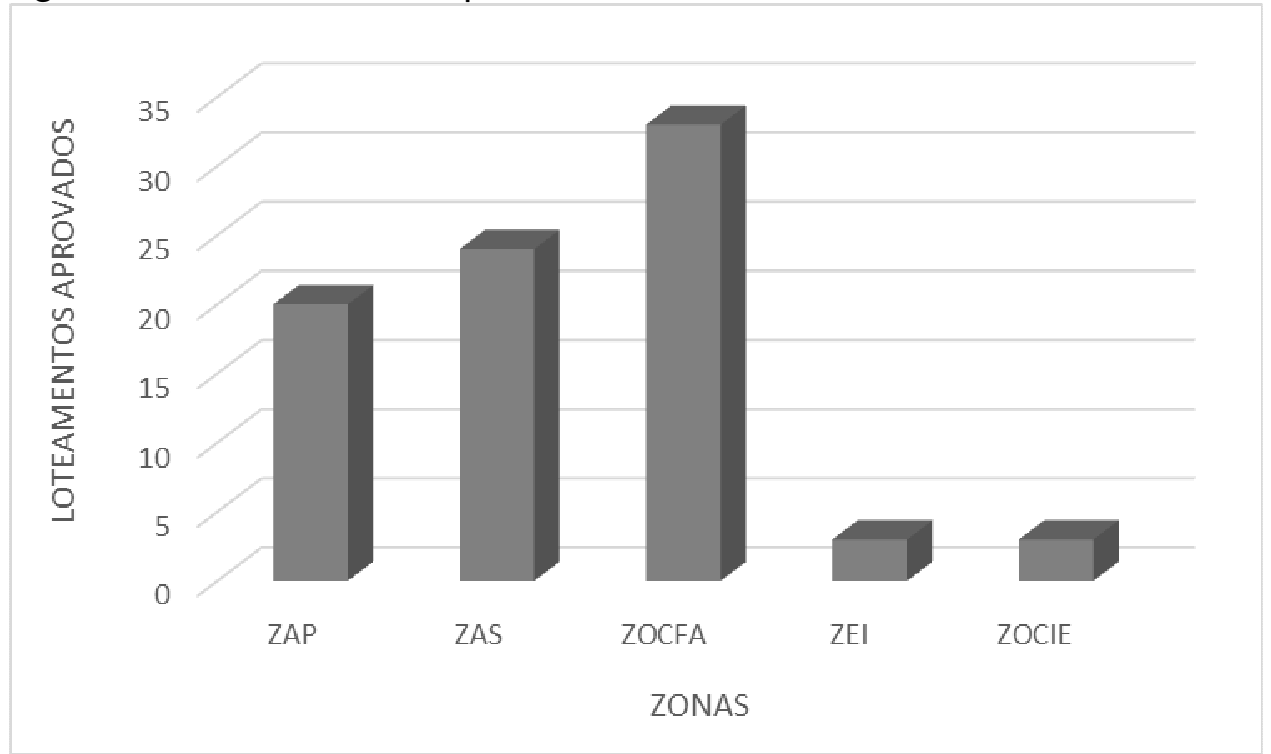

Fonte: IPPAP,2016.

Observa-se que nas zonas de adensamento prioritário e secundário (ZAP e ZAS) foram aprovados 20 e 24 loteamentos, respectivamente. Na Zona Especial Industrial (ZEI) foram aprovados 2 loteamentos e na Zona de Ocupação Controlada por Infraestrutura também foram aprovados 3 loteamentos. Já a Zona de Ocupação Controlada por Fragilidade Ambiental (ZOCFA) é a que possui o maior número de loteamentos aprovados, 33 ao total.

Dessa forma, mesmo tendo sido aprovados novos loteamentos nas áreas onde deve haver um adensamento populacional, as áreas onde a ocupação deve ser controlada devido à fragilidade ambiental, foram as que mais receberam novos loteamentos, absorvendo cerca de $40 \%$ de todos os loteamentos aprovados no período.

Como estabelecido pelo Plano Diretor, na ZOCFA poderá ser aplicado o instrumento de Zona Especial de Interesse Social (ZEIS), ocorre que além de compor áreas de Fragilidade Ambiental, parte significativa da ZOCFA concentra a população de menor renda do município, principalmente na região Norte.

Sendo assim, observa-se que há uma tendência à segregação socioescpacial da população de baixa renda nas áreas de fragilidade ambiental, estimulada pela produção de moradia pelo Estado para a população de baixa renda.

Em contrapartida, mesmo com a criação de loteamentos nas zonas de adensamentos primário e secundário, verifica-se a presença de grandes áreas vazias de especulação imobiliária, os chamados vazios urbanos. Estas áreas Número Especial da Revista Estudos Geográficos - XIII Seminário da Pós-Graduação em Geografia, Rio Claro, 15(0): 17-33, jan./jun. 2017 (ISSN 1678—698X) http://www.periodicos.rc.biblioteca.unesp.br/index.php/estgeo 
representam cercam de $20 \%$ do total da mancha urbana, podendo absorver parte significativa dos loteamentos aprovados no período de 2006 a 2016, sem que seja necessário um crescimento urbano para a periferia e em áreas de fragilidade ambiental.

A figura 5 apresenta espacialmente a localização dos loteamentos aprovados em relação ao zoneamento urbano.

Figura 5 - Zoneamento urbano e loteamentos aprovados na cidade de Piracicaba entre 2006 e 2016.

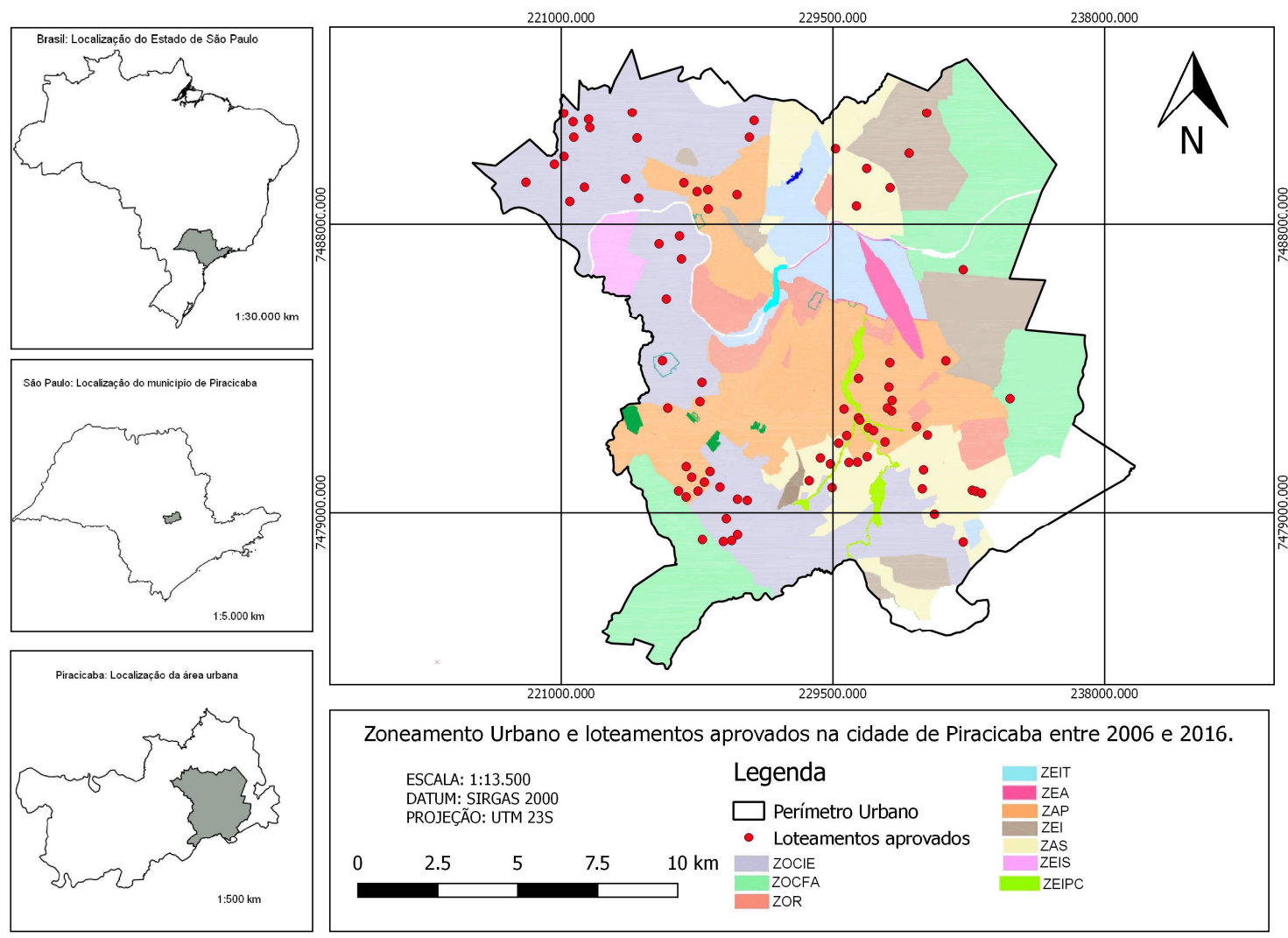

Fonte: LEI COMPLEMENTAR № 186/2006; IPPLAP, 2016. Elaboração: Os autores, 2017.

A partir da figura 5 podemos constatar que parte significativa dos loteamentos aprovados estão localizados na ZOCFA; especificamente na área Norte se observa loteamentos aprovados próximo ao perímetro, exercendo pressão para o aumento do perímetro urbano na cidade.

Número Especial da Revista Estudos Geográficos - XIII Seminário da Pós-Graduação em Geografia, Rio Claro, 15(0): 17-33, jan./jun. 2017 (ISSN 1678-698X) http://www.periodicos.rc.biblioteca.unesp.br/index.php/estgeo 


\section{CONSIDERAÇÕES FINAIS}

Este artigo apresentou uma avaliação da eficácia do zoneamento urbano como instrumento urbanístico, uma vez que a caracterização sobre o uso e ocupação do solo nas porções do território de Piracicaba são fundamentais para determinar a ação dos agentes sociais e econômicos.

Partiu-se da premissa de que o zoneamento urbano traz uma clara caracterização das condições físicas, econômicas e sociais do território e, portanto, suas delimitações de uso e ocupação do solo seriam eficazes para melhoramento da qualidade urbana.

No entanto, observou-se que $40 \%$ de todos os loteamentos aprovados no período de 2006 e 2016 foram instalados em áreas de ocupação controlada devido às fragilidades ambientais que apresentam. Isso demonstra as intencionalidades do poder público municipal em favorecer determinados agentes imobiliários.

Outro aspecto a se considerar é a presença dos vazios urbanos nas áreas de adensamentos prioritário e secundário, pois estes seriam capazes de absorver parte significativa dos loteamentos aprovados no período. Essa absorção propiciaria um adensamento na área central da cidade, com a utilização otimizada das infraestruturas já instaladas e controlaria a ocupação das áreas de fragilidade ambiental.

Dessa forma, esse trabalho se apresenta como uma parte da discussão da temática da produção de novos loteamentos nas cidades e busca estimular novos pesquisas na área, aprofundando os debates sobre as cidades brasileiras.

\section{AGRADECIMENTOS}

Agradecemos à Fundação de Amparo à Pesquisa do Estado de São Paulo FAPESP pelo o apoio financeiro, processo 2014/24892-0.

\section{REFERÊNCIAS}

BRAGA, R. Política urbana e gestão ambiental: considerações sobre o plano diretor e o zoneamento urbano. In: CARVALHO, P. F. de; BRAGA, R. (orgs.) Perspectivas de Gestão Ambiental em Cidades Médias. Rio Claro: LPM-UNESP, 2001.

Número Especial da Revista Estudos Geográficos - XIII Seminário da Pós-Graduação em Geografia, Rio Claro, 15(0): 17-33, jan./jun. 2017 (ISSN 1678-698X) http://www.periodicos.rc.biblioteca.unesp.br/index.php/estgeo 
BRAGA, R. Plano Diretor Municipal: três questões para discussão. Caderno do Departamento de Planejamento, Presidente Prudente, v. 1, n.1, 1995.

BRASIL. Estatuto da cidade. 2001.

CORRÊA, R. L. O Espaço Urbano. Editora ática S.A. São Paulo, 1989.

COSTA, H. S. M; MENDONÇA, J. G. Breve trajetória de ideias acerca da dinâmica imobiliária urbana. In MENDONÇA, J. G.; COSTA, H. S. M.(Org.) Estado e capital imobiliário: convergências atuais na produção do espaço urbano brasileiro. 1 . ed. Belo Horizonte/Arte, v.1, 2011.352p.

DAINEZI, D. P. Análise dos processos e instrumentos de ordenação do território: comparação entre Brasil e Portugal. Qualificação de Tese. UNESP, 2012.

GONÇALVES, J. C. A especulação imobiliária na formação de loteamentos urbanos: um estudo de caso. E-Papers: Rio de Janeiro, 2010.

INSTITUTO BRASILEIRO DE GEOGRAFIA E ESTATÍSTICA. Caracterização geral da cidade. Acessado em: 05/01/2016. Disponível em:

http://cidades.ibge.gov.br/painel/painel.php?codmun=353870

INSTITUTO DE PESQUISAS E PLANEJAMENTO DE PIRACICABA. Loteamentos Implantados com Aprovação Final - 2002 a 2015. Acessado em: 02/01/17.

Disponível em:

http://ipplap.com.br/docs/Loteamentos\%20Implantados\%20com\%20Aprovacao\%20F in al\%20-\%202002\%20a\%202015.pdf

INSTITUTO DE PESQUISAS E PLANEJAMENTO DE PIRACICABA. GRAU DE URBANIZAÇÃO NO MUNICÍPIO DE PIRACICABA (EM \%) - 1980 A 2000 E 2010 A 2014, 2015e.

INSTITUTO PÓLIS. Relatório 1 - Leitura Técnica e Participativa. Revisão do Plano Diretor de Desenvolvimento de Piracicaba. Piracicaba: Pólis, 2003.

MAGALHÃES, F. N. C; FILHO, J. B. M. T; SILVA, H. Valorização Imobiliária e produção do espaço: novas frentes na RMBH. In MENDONÇA, J. G.; COSTA, H. S. M.(Org.). Estado e capital imobiliário: convergências atuais na produção do espaço urbano brasileiro. 1. ed. Belo Horizonte: C/ Arte, 2011. v. 1. 352p.

MONTE-MOR, R. L. M Planejamento Urbano no Brasil: Emergência e Consolidação. In Revista Etc., espaço, tempo e crítica - Revista Eletrônica de Ciências Sociais Aplicadas e outras coisas, n. 1(4), vol. 1, 15 de Junho de 2007.

MONTEIRO, T. V. A. Contributo para a reabilitação sócio territorial de favelas. Universidade de Aveiro, 2009. 
PIRACICABA. Lei Complementar no 186, de 10 de outubro de 2006.

REZENDE, D. A; ULTRAMARI, C. Plano diretor e planejamento estratégico municipal: introdução teórico-conceitual. Rev. Adm. Pública, Rio de Janeiro, v. 41, n. 2, Apr., pp. 255-271. 2007

SANTOS, M. Economia Espacial. Críticas e Alternativas. São Paulo: Edusp, 2003 [1979].

SANTOS, S. S. Uma cidade à venda? Capital Imobiliário, Poder público e produção do espaço em Florianópolis a partir da década de 1980. Revista de Desenvolvimento Econômico. Ano XIV, n. 26, Salvador, Ba, 2012.

SINGER, P. O uso do solo urbano na economia capitalista. MARICATO, E. (Org.), A produção capitalista da casa (e da cidade) no Brasil industrial. São Paulo AlfaÔmega, 1979. 